\title{
Les condicions socials de la lluita contra la pobresa. Una crítica de les hipòtesis dels capitals individuals i de la mobilitat ${ }^{1}$
}

\section{Xavier Rambla}

Universitat Autònoma de Barcelona. Departament de Sociologia

Seminari d'Anàlisi de la Política Social. Institut de Govern i Polítiques Públiques

08193 Bellaterra (Barcelona). Spain

xavier.rambla@uab.es

\section{Resum}

L'article exposa diverses crítiques de les hipòtesis sobre el capital social, el capital humà i la mobilitat social (de posició i d'ingrés), les quals sovint es presenten com un argument empíric a favor de l'estratègia de combatre la pobresa ensenyant les persones pobres a utilitzar aquests capitals individuals per aprofitar els canals de la mobilitat. Arriba a la conclusió que aquestes crítiques posen en dubte l'efectivitat d'aquesta estratègia.

Paraules clau: desigualtats, pobresa, estructura social, capital humà, capital social.

Resumen. Las condiciones sociales de la lucha contra la pobreza. Una crítica a las hipótesis de los capitales individuales y de la movilidad

El artículo expone varias críticas de las hipótesis sobre el capital social, el capital humano y la movilidad social (de posición e ingreso), que a menudo se presentan como un argumento empírico a favor de la estrategia de combatir la pobreza enseñando a las personas pobres a utilizar estos capitales individuales para aprovechar los canales de movilidad. Llega a la conclusión de que estas críticas ponen en tela de juicio la efectividad de esta estrategia.

Palabras clave: desigualdades, pobreza, estructura social, capital humano, capital social.

1. Aquest treball s'emmarca en el projecte de recerca «Globalización y desigualdades en América Latina: formación, contenidos e impactos de las políticas educativas y de lucha contra la pobreza en Argentina, Brasil y Chile», finançat pel Ministeri de Ciència i Tecnologia i el FEDER (projectes I+D, amb referència SEC2002-02480), que duu a terme el Seminari d'Anàlisi de la Política Social (del Departament de Sociologia i de l'Institut de Govern i Polítiques Públiques de la UAB). N’he pogut presentar i discutir diverses versions anteriors a la II Conferencia Internacional "Desarrollo Humano Sostenible, Sociología y Sociedad», Càtedra Internacional UNESCO «Desenvolupament Humà Sostenible» i Xarxa UNES$\mathrm{CO} /$ UNITWIN «Medeuramèrica per al Desenvolupament Humà» (l'Havana, 07-2002, on vaig poder assistir gràcies a un ajut per a viatges del Departament de Sociologia de la $\mathrm{UAB}$ ), a un dels seminaris del SAPS (UAB, 11-2002). Agraeixo els comentaris que se m'han fet totes tres vegades, i al IV Congrés Català de Sociologia (Reus, 2003). Agraeixo també els comentaris dels avaluadors anònims de Papers. Revista de Sociologia. 
Abstract. The social conditions of anti-poverty policies. A critique of the hypotheses about individual capitals and social mobility

The article presents several critiques of the hypotheses on social capital, human capital and social mobility (with respct to position and income). These theses are often seen as an empirical argument in favor of the anti-poverty strategy that aims to teach the poor how to use these individual capitals in order to avail of the channels of mobility. The conclusion states that these critiques cast doubt on the effectiveness of this strategy.

Key words: inequalities, poverty, social structure, human capital, social capital.

\section{Sumari}

La lluita contra la pobresa

Eixamplen els capitals individuals les vies de mobilitat?
Conclusions i implicacions

Bibliografia

Algunes objeccions a les hipòtesis dels capitals individuals i la mobilitat

La pobresa ha tornat a ser objecte de les declaracions polítiques internacionals des de fa uns quants anys. A diferència de la dècada de 1980 i de començament de la de 1990, avui en dia els principals governs, les Nacions Unides i les altres organitzacions supragovernamentals tenen molts dubtes sobre la capacitat del lliure mercat per eradicar-la. La pobresa, d'altra banda, ha esdevingut un dels objectes d'estudi més interdisciplinaris de les ciències socials. Tant és així que esdevé molt difícil parlar-ne sense evocar els termes econòmics que fan referència a la distribució dels recursos i els termes sociològics amb què designem l'estructura social, o també els termes pedagògics que identifiquen les formes d'aprendre.

Aquesta oscil-lació entre la fe i l'escepticisme en el poder dels esforços individuals i els mercats per generalitzar la prosperitat és un episodi més dels moviments intel-lectuals que han fet aflorar i han submergit aquests dubtes des de fa ben bé dos-cents anys. De fet, als anys seixanta, la majoria de les recomanacions oficials i acadèmiques donaven per suposat que els estats de benestar i l'ajut internacional podien resoldre el problema de la pobresa; en canvi, als anys vuitanta, s'esperava que els mercats aconseguissin aquesta fita, això sí, sempre que els governs sabessin deslliurar-los d'un cúmul de càrregues i de rigideses. Però el que potser és més peculiar del darrer canvi d'opinió és un cert consens sobre les maneres de combatre la pobresa. Tot i que la discrepància en aquesta qüestió és tan antiga com el mateix debat, a hores d'ara s'estén una vaga esperança en la possibilitat que les persones pobres aprenguin per si mateixes a sortir del mal pas. Aquesta expectativa, tanmateix, recolza en unes hipòtesis sobre els factors de la pobresa, així com sobre l'efecte de diversos possibles remeis sobre aquests factors. A grans trets, s'admet que si aconseguim universalitzar el coneixement, gairebé tothom aprendrà a enginyar-se la seva 
manera de guanyar-se la vida; encara més, sovint es dóna per descomptat que la causa de la pobresa rau més aviat en la ignorància que no pas en la manera de distribuir els recursos. L'article que llegiu intenta esclarir en què es basa aquesta idea, i arriba a unes conclusions bastant escèptiques al respecte.

En particular, trobareu a les pàgines següents una comparació de les propostes polítiques contemporànies de lluita contra la pobresa i la discussió d'una de les hipòtesis proposades per analitzar-la. Aquesta manera de delimitar el tema crida, doncs, l'atenció sobre el diagnòstic i més endavant recorda la seva relació amb les propostes. Per evitar malentesos, voldria afegir en aquesta introducció tres comentaris previs. En primer lloc, com diuen explícitament els discursos polítics, l'economia proporciona moltes mesures i controvèrsies sobre les connexions entre el creixement econòmic i l'alleujament de la pobresa, però la majoria d'experts està d'acord que aquestes connexions no esgoten l'explicació ni el camp de les intervencions necessàries. En segon lloc, també és notable l'adhesió que han despertat les definicions de la pobresa que en tenen en compte diverses dimensions i processos. S'entén que la pobresa sorgeix quan les persones no poden satisfer les seves necessitats pel que fa a l'ingrés, l'educació, la salut, les condicions laborals, les relacions socials o l'accés als serveis i recursos bàsics. Per anomenar les diverses maneres de combinar aquests factors s'utilitzen termes com ara "pobresa humana», "exclusió» o "vulnerabilitat», però aquí em limitaré a fer servir el terme "pobresa» en un sentit general que al.ludeix alhora als denominadors comuns d'aquestes visions d'una realitat polifacètica. Tanmateix, malgrat la importància d'aquests punts de convergència, intentaré mostrar de quina manera dues posicions es confronten i es contraposen en molts altres aspectes. En tercer lloc, voldria apuntar una distinció important entre les pretensions de l'article i altres possibles aproximacions a l'estudi de la pobresa. D'aquesta manera, tot i que he il.lustrat la presentació de les propostes amb les tesis de diversos autors, no és la meva intenció revisar el pensament polític sobre la pobresa d'una manera sistemàtica; igualment, tot $\mathrm{i}$ que he esmentat algunes connexions entre aquestes hipòtesis d'anàlisi i les recomanacions que s'hi han inspirat, no és tampoc la meva intenció classificar les diverses estratègies de lluita contra la pobresa.

El text consta de tres grans parts. La primera distingeix dues orientacions de les propostes contemporànies de lluita contra la pobresa segons si responen a una lògica de la inducció o de l'extensió de la ciutadania. La segona part discuteix la hipòtesi que els capitals humà i social obren el camí de la mobilitat social o de la sortida de la pobresa. Finalment, la conclusió resumeix breument la qüestió i procura mostrar algunes relacions específiques entre l'anàlisi i les propostes.

\section{La lluita contra la pobresa}

A primera vista, és unànime la convicció que les institucions polítiques han de combatre totes les cares de la pobresa tenint en compte com s'acumulen els seus factors en uns determinats col-lectius socials. Però l'acord es trenca a l'hora 
d'assenyalar quin mecanisme pot ser més decisiu per contrarestar aquest fenomen. Aquesta discrepància es pot resumir en poques paraules apuntant que algunes propostes de la lluita contra la pobresa recomanen en darrera instància que cal induir els pobres a superar la seva situació, mentre que unes altres col-loquen l'acció política estatal en aquesta darrera instància decisiva. Es tracta de dues lògiques d'actuació diferents, que coincideixen a observar diverses vessants del problema, però no ordenen les solucions segons un mateix ordre de prioritats. Denominaré la primera com la "lògica de la inducció», perquè espera induir els pobres a sortir-se'n pel seu compte. El terme «inducció», a més, també evoca el procediment metodològic d'extraure conclusions a partir de sumar casos individuals. Doncs bé, si se’m permet la metàfora, la lògica de la inducció també confia que s'eradicarà la pobresa si aconseguim que totes les persones pobres aprenguin individualment les maneres de superar els seus problemes. I definiré com a «lògica de l'extensió de la ciutadania» la segona, ja que dóna la màxima importància a la universalització dels drets socials, a més del que puguin fer individualment les persones que veuen malmesos els seus drets perquè són pobres.

La «logica de la inducció» combina els principis de l'acció selectiva i de l'activació. L'acció selectiva persegueix la màxima eficiència de l'actuació tot delimitant el col-lectiu més necessitat, d'acord amb un (p. ex., ingrés) o diversos (p. ex., ingrés, educació i salut) criteris, i concentra tot l'esforç en aquest grup. L'activació consisteix a estimular un col-lectiu perquè aprofiti els recursos de què disposa per superar les seves privacions. Normalment, l'activació s'empra per afavorir la inserció laboral, però també és aplicable a organitzar un negoci propi o animar algú perquè la seva prole vagi a escola o perquè sanegi el seu barri.

El Banc Mundial² (2001) defineix la inducció com l'ampliació de les oportunitats dels pobres, la seva potenciació i el reforç de la seva seguretat. Per la seva banda, la CEPAL ${ }^{3}$ (2000) ha esdevingut un dels principals promotors institucionals de l'acció selectiva (o «focalización») per contrarestar la pobresa. Val a dir que avala la seva proposta amb el sòlid argument que és la millor manera d'aprofitar al màxim uns recursos col-lectius escassos en bé dels grups que encara pateixen més escassesa dins de l'escassesa. L'activació, en fi, s'ha

2. «La pobresa és el resultat de processos econòmics, polítics i socials [...] Per això és crucial l'ampliació de les oportunitats (estimulant el creixement, fent que els mercats funcionin millor per als pobres i reforçant els seus actius) per reduir la pobresa. [...] Per això és crucial la potenciació (empowerment) dels pobres (fent que l'estat i les institucions socials siguin més responsables davant d'ells) per reduir la pobresa [...] Per això és crucial reforçar la seguretat (reduint el risc de guerra, malaltia, crisi econòmica o desastre natural) per reduir la pobresa» (World Bank, 2001).

3. «La universalidad no es contraria a la posibilidad de establecer criterios de selectividad. Además, ante la escasez de recursos públicos, en particular durante las crisis y los ajustes económicos y en economías poco desarrolladas, se impone la selectividad como forma de superar que los servicios sociales lleguen a la población más pobre y se logre mayor equidad y eficiencia en el uso de los recursos» (CEPAL, 2000). 
incorporat a la panòplia d'instruments que molts organismes supragovernamentals $\left(\mathrm{OECD}^{4}, 2001 \mathrm{a}\right.$; CEPAL ${ }^{5}, 2002$; CE Lisboa $\left.{ }^{6}, 2000\right)$ fan servir o proposen, en la majoria de casos pensant en el mercat laboral i la formació dels treballadors.

La «lògica de l'extensió de la ciutadania» reclama dels estats les decisions explícites de garantir els drets socials. Els termes de "desenvolupament humà» o de "treball decent" amb què el PNUD $^{7}$ (1997) o l'OIT ${ }^{8}$ (ILO, 2001), respectivament, hi fan referència al.ludeixen fins i tot al caràcter moral d'aquest compromís polític. El primer amida els esforços per combatre la pobresa humana amb uns nivells similars de desenvolupament econòmic, i el segon sosté que les polítiques d'estendre la protecció social a tots els treballadors haurien de contribuir molt a reduir la pobresa.

4. «The strong relationship between employment status and poverty transitions is in line with the general thrust of employment-oriented social policy. However, the high incidence of poverty among working households indicates the need for policies that improve employment retention and enhance movement up job ladders for individuals in houses that exit poverty $[. .$.$] The empirical analyses also confirm [that] a more extensive welfare state redu-$ ces poverty in a single year [and] also tends to reduce poverty persistence» (OECD, 2001a).

5. «En las teorías sobre el capital humano se destacan dos elementos fundamentales que han de considerarse en la lucha contra la pobreza: primero, que las diferencias en los logros educativos constituyen el factor más determinante de las desigualdades y del acceso al bienestar y, segundo, que la satisfacción de las necesidades básicas tiene un enorme potencial productivo individual y social, en la medida en que acrecienta las capacidades de las personas para contribuir al crecimiento económico y satisfacer sus propias necesidades» (CEPAL, 2002: cap 3).

6. «32. La nueva sociedad basada en el conocimiento ofrece un enorme potencial para reducir la exclusión social, tanto mediante la creación de las condiciones económicas para una mayor prosperidad con mayores niveles de crecimiento y empleo, como propiciando nuevas formas de participación en la sociedad. Al mismo tiempo, se corre el riesgo de dar pie a una diferencia cada vez mayor entre quienes tienen acceso a los nuevos conocimientos y quienes quedan excluidos. [...] Para evitar este riesgo y aprovechar al máximo este nuevo potencial, deben hacerse esfuerzos para mejorar las cualificaciones, promover un acceso más amplio a los conocimientos y oportunidades y luchar contra el desempleo: la major salvaguardia contra la exclusión social es un trabajo» (Consejo Europeo de Lisboa, 2000).

7. «El progrés en la reducció de la pobresa d'ingrés i el progrés en la reducció de la pobresa que afecta les eleccions i les oportunitats humanes no sempre són paral.lels [...] Comparant l'Índex de Pobresa Humana i l'Índex de Desenvolupament Humà s'observen aguts contrastos en alguns països. Aquestes diferències haurien d'alertar els polítics de la necessitat de distribuir millor el desenvolupament humà, és a dir, fer-lo més favorable als pobres» (PNUD, 1997).

8. «26. Translating the concept of decent work into a policy framework for poverty reduction will require attention to its four broad and interconnected components, as follows: employment, standarrds and fundamental principles and rights at work, social protection and social dialogue.

27 . With respect to poverty reduction, the immediate goal will certainly involve a combination of measures to promote productive employment and social protection, but rights and representation are needed to achieve these advances. Realizing the mutually reinforcing potential of these dimensions of decent work will need a focus on the institutional conditions that create opportunities for women and men and exploit their capabilities through work» (ILO, 2001: 8). 
La mateixa varietat de les citacions mostra el predomini de la primera perspectiva. En general, totes dues es presenten com els «nous» remeis de la pobresa, però l'extensió de la ciutadania és tan sols un epígraf més dins de la llarga llista d'objectius de dues agències de l'ONU, mentre que la idea de la inducció encapçala molts informes específics i figura entre les condicions dels crèdits del Banc Mundial o entre els criteris de la convergència europea. D'altra banda, malgrat l'aire de novetat amb què aquestes propostes es presenten, no és possible entendre-les al marge de les tradicions del pensament polític que evoquen d'una manera més o menys directa. De fet, com els partidaris de la inducció avui en dia, des de fa dos-cents anys, molts pensadors han volgut combatre la pobresa ensenyant els pobres a deseixir-se millor. Normalment, l'argumentació a favor d'aquesta línia d'acció destaca la fluïdesa del creixement productiu i de l'estructura social, alhora que dóna la darrera paraula a les qualitats personals dels pobres. Se'n deriven recomanacions pragmàtiques d'educar-los perquè treballin per si mateixos, així com el dubte que l'acció estatal directa de compensar les seves mancances sigui veritablement efectiva.

Acabaré aquest apartat recollint algunes referències històriques a les dues lògiques d'actuació. Aquests exemples indiquen de quina manera s'han anat travant les connexions entre unes afirmacions de fet $\mathrm{i}$ unes justificacions del que cal fer. Així, Thomas Malthus va dibuixar un diagnòstic molt pessimista, per tal com dubtava que els recursos cresquessin al mateix ritme que la població. Tanmateix, trobava una escletxa per a l'esperança en la possibilitat que s'abolissin les lleis d'assistència parroquial als pobres, de tal manera que aquests disposessin de llibertat per assentar-se a conrear els camps on creguessin, o bé fossin internats en uns asils de «tracte dur» si no es veien capaços d'incrementar els recursos alimentaris treballant amb aquesta autonomia (Malthus, 1985 [1798]: 62-63). Alfred Marshall (1966 [1890]: VI, XIII) era molt més optimista sobre el creixement econòmic, per tal com esperava que la riquesa relativa s'estengués cap avall fins a convertir tot home en un "cavaller econòmic» autònom. Però per ell creixien alhora el dividend nacional i l'energia, la intel.ligència i l'amor propi dels pobres, la qual cosa reforçava la seva laboriositat, temperància i capacitat d'estalvi. De la mateixa manera, Joseph Schumpeter és conegut per les teories que el cicle econòmic desfermava una destrucció creativa i que l'èxit de l'empresa capitalista depenia també de l'arrelament de l'esperit empresarial. Aquestes hipòtesis eren complementàries amb l'observació que les classes socials eren obertes, com un hotel o un autobús, de tal manera que sempre estaven plenes de persones diferents (Schumpeter, 1986 [1950]: 131); el moviment entre les unes i les altres depenia de la capacitat individual per prosperar. Aquests tres autors donen exemples de la construcció històrica de la «lògica de la inducció». Les seves anàlisis coincideixen a detectar una voluntat de les persones per treballar pel seu propi bé i, per tant, dedueixen que la incapacitat per actuar així és una de les causes principals de la pobresa. Només el pessimista Malthus hi va afegir una recomanació sobre com es podia induir els pobres a sortir del forat, ja que els optimistes Marshall i Schumpeter 
suposaven que aquesta habilitat s'aprenia espontàniament. Les propostes contemporànies matisen la "duresa malthusiana», però cerquen la manera d'ensenyar la "laboriositat marshalliana», i per tant activar els "moviments schumpeterians» entre posicions.

Els arguments a favor d'estendre la ciutadania sovint s'han limitat a recordar la distància que separa les intencions de la realitat, però ja fa uns cinquanta anys que també han anunciat la possibilitat de superar-la gràcies a l'Estat de benestar. Condorcet, Engels i Thomas Marshall, en diversos moments, han suposat que els factors estructurals determinen la pobresa amb més pes que els personals $i$, en conseqüència, han proposat canvis de l'estructura social per eradicar aquesta pobresa. Filòsof i matemàtic, Condorcet va proclamar que la desigualtat s'establia entre categories de persones i també respecte als mínims necessaris per a una vida digna. La primera es mesurava segons la dispersió estadística, mentre que la segona responia a la distància respecte a una unitat que representava els valors dignes. D'acord amb aquesta noció, volia prendre les mides del progrés al llarg de tres dimensions: la disminució de la desigualtat entre nacions, l'avenç de la igualtat a dins d'un mateix poble, i a través (entre altres coses) d'una veritable igualtat entre els sexes, el perfeccionament de l'home, el qual «tornés comunes les virtuts domèstiques, veritable fonament de totes les altres, i empenyés la instrucció tot generalitzant-la» (Condorcet, 1793, cap. X). Engels va completar aquesta esperança que el progrés duria una societat més justa amb l'observació de les condicions de vida dels obrers industrials. El seu argument adduïa que el capital condemna els obrers a la fam o els col-loca a frec de patir-la, i reclamava, doncs, la supressió d'aquesta mena de relacions econòmiques (Engels, 1965 [1845]: 46). Cent anys després, Thomas Marshall (1998 [1950]: 40) cercava la manera que la pobresa fos evitable en les societats capitalistes mitjançant la consciència social. Aquesta era el reconeixement dels factors pels quals els rics depenien també dels pobres, o els capitalistes dels proletaris en l'esquema dual de classes. Entenia Marshall que la protecció contra les malalties infeccioses, la seguretat d'una previsió social col.lectiva, els beneficis d'una població educada o també l'estímul d'una demanda efectiva mínima, en darrera instància acabaven operant pel bé de tothom. Malgrat que al segle XIX no es comprenia bé aquesta interdependència, la mateixa extensió de la ciutadania social acabava fent palès que «la reducció de les classes, com la del fum, es converteix en una meta que cal perseguir, sempre que resulti compatible amb l'eficàcia contínua de la màquina social». Les propostes actuals, doncs, intenten assolir l'«ideal» de Condorcet i resoldre el «problema» d'Engels amb l'Estat de benestar. A diferència de Condorcet i de Th. Marshall, però, desconfien de les forces teleològiques del progrés social.

\section{Eixamplen els capitals individuals les vies de mobilitat?}

La lògica de la inducció proposa empènyer els pobres perquè aprenguin a guanyar-se la vida. Aquesta estratègia expressa una notable confiança en a) la possibilitat d'engegar algun mecanisme per induir els individus a prosperar, i 
b) l'existència d'algun marge de maniobra dels individus per alterar la seva dotació de recursos. En contraposició, la lògica de l'extensió de la ciutadania proposa generalitzar els drets socials, perquè, entre moltes altres coses, recolza en els dubtes sobre aquesta possibilitat i sobre l'existència d'aquest marge. Doncs bé, les teories dels capitals individuals (humà i social) i la tesi que la mobilitat és la mesura moderna de la desigualtat intenten satisfer aquella confiança de la lògica de la inducció. Una bona part, doncs, del crèdit d'aquesta estratègia ha de dependre de la validesa d'aquestes tesis.

\section{El capital humà}

Gary Becker (1987) ha especificat els mecanismes pels quals, a parer seu, el capital humà provoca les desigualtats. El capital humà sorgeix de les habilitats adquirides pels individus, ja que el mercat laboral assigna més ingressos als qui tenen més estudis. Llavors, la formació és una mena d'inversió individual els beneficis de la qual són els ingressos durant la vida laboral. Segons aquest autor, el capital humà determina que, al llarg del temps, la desigualtat de les rendes familiars i la mobilitat entre generacions tendeixin a equilibrar-se. Entre els factors d'aquest equilibri figuren moltes circumstàncies, des de la sort fins al creixement econòmic o la discriminació. Però els factors principals depenen del comportament dels individus. D'aquesta manera, la mobilitat entre generacions és el producte de la capacitat de les famílies per fer la transmissió hereditària de les seves dotacions i de la propensió a invertir en els seus fills. La primera facultat, com és obvi, està més relacionada amb la propietat que amb el capital humà, però la segona és el producte de la inversió familiar en aquest capítol.

A partir d'aquest raonament, Becker arriba a hipòtesis molt més precises sobre la discriminació i l'acció de l'estat. En tota anàlisi de la discriminació, argumenta, cal distingir entre les restriccions legals de les oportunitats d'una minoria i les decisions individuals dels membres d'aquesta minoria, perquè molt sovint les minories accedeixen a menys recursos a causa de la seva feble inversió en capital humà més que de l'aplicació desigual de les lleis. L’acció de l'estat destinada a fomentar la igualtat mitjançant els impostos i les despeses progressives, d'altra banda, pot ser contraproduent, en la mesura que redueix la diferència d'ingressos segons els estudis i, per tant, desanima la inversió en capital humà? .

9. A una conclusió anàloga va arribar Wilenski (1975: 109) tot revisant els experiments de l'impost negatiu als Estats Units. El govern va comparar el comportament d'un grup de llars de baix ingrés a les quals va atorgar un subsidi durant tres anys amb el comportament d'altres llars del mateix ingrés que no rebien cap subsidi. Els resultats van palesar que les dones de les llars subsidiades van reduir el seu nombre d'hores de treball remunerat, i els fills joves van trigar més temps a buscar feina. 


\section{El capital social}

Coleman (1988) ha complementat aquesta anàlisi amb la seva hipòtesi sobre el capital social. Aquest està configurat per la xarxa de relacions personals dels individus i per la seva confiança en la reciprocitat aliena donades unes condicions. Molts canvis socials actuals amenacen de destruir el capital social, tal com palesen les fragmentàries xarxes socials de molts pobres o de molts barris degradats a les grans ciutats. Però també es poden identificar altres factors que contribueixen a crear-ne, com ara pot ser l'ethos comunitari de les escoles privades catòliques nord-americanes. L'efecte del capital social sobre la pobresa, doncs, variarà d'acord amb la importància més o menys gran d'aquestes institucions, però també de la seva mateixa influència sobre l'acumulació del capital humà.

Ateses aquestes circumstàncies, l'acció estatal podria perjudicar l'estoc de capital social d'un país. Si més no, l'extensió dels drets de ciutadania mereix aquesta reserva a ulls de Coleman (1988). O bé, Murray (1999: 14) es preocupa en la mateixa línia pels efectes perversos de l'anomenada "custòdia democràtica", que consisteix a donar subsidis i aillar la infraclase. Als Estats Units, no ha impedit pas que la cultura violenta d'aquest grup s'hagi estès com una taca d'oli des de la minoria afroamericana fins a la majoria blanca, tal com indica l'augment dels índexs de criminalitat, d'abandonament de l'ocupació i d'embaràs a fora del matrimoni. Fukuyama (2001: 18) rebla el clau adduint que el capital social és un subproducte de l'acció, perquè els individus aprenen a conrear les seves relacions i a confiar en les altres persones després que fracassen les seves estratègies egoistes (p.ex., experimentant diverses vegades els perjudicis del dilema del presoner); en conseqüència, la protecció estatal «altruista» entorpeix aquest aprenentatge.

Reconeixent alguns d'aquests eventuals obstacles, en els darrers anys s'han precisat diverses hipòtesis sobre una virtual contribució de l'estat a la lluita contra la pobresa mitjançant diversos possibles efectes beneficiosos de les polítiques públiques sobre el capital social. Narayan (1999) ha establert una tipologia mundial de les condicions socials de la lluita contra la pobresa. Les correlacions estadístiques entre, d'una banda, la igualtat social, la confiança i la implicació cívica, i, d'una altra, el creixement econòmic, indiquen, segons aquest autor, que la prosperitat econòmica depèn del bon govern (respectuós dels drets civils, competent, transparent, mereixedor d'autoritat i dotat de recursos) i de l'anomenat "capital social pont» (que estableix vincles entre els grups diferenciats més clarament en una societat). El bon govern i l'absència d'aquest capital provoquen una circumstància d'exclusió de masses (EUA), el mal govern i la mateixa manca de ponts duen al conflicte (Índia o Colòmbia), i el mal govern en un context on abunden els ponts obliga les societats a deseixirse per perilloses vies informals com ara la màfia (Àfrica o Rússia). En conseqüència, les mesures més convenients per alleujar la pobresa haurien de reforçar les capacitats dels pobres (perquè empenyin vers el bon govern) i establir els fonaments del capital social pont (generalitzant la informació sobre les opor- 
tunitats materials, eixamplant les vies de participació, cercant mecanismes de gestió dels conflictes, promovent l'alfabetització, inculcant un currículum escolar favorable a la cohesió social, etc.).

Atria (2003) també ha desglossat el concepte de capital social per esbrinar com pot actuar de vehicle de les polítiques contràries a la pobresa. La seva anàlisi assenyala dos components del capital social: l'amplitud de les xarxes socials i la capacitat de mobilitzar recursos. Als indigents (o a les persones que disposen d'uns ingressos ínfims) els manquen tots dos components, i per tant necessiten, abans de res, ampliar les seves xarxes mitjançant l'accés als serveis socials bàsics. En canvi, els pobres pròpiament dits (els qui se situen just a sota de la meitat de l'ingrés mitjà) disposen de xarxes més consolidades, però d'una feble capacitat de mobilització; per tant, necessiten que s'escolti la seva veu i que se'ls ensenyi a utilitzar els seus recursos autònomament (2003: 588).

Si recapitulem l'argumentació, obtenim el mecanisme causal següent: les persones disposen de recursos per afrontar l'adversitat econòmica pel seu compte bo i formant-se o consolidant les seves xarxes socials; la intervenció estatal excessiva amenaça aquests recursos en devaluar els beneficis de les inversions educatives o aturar la gènesi del capital social; però una acció estatal mínima pot catalitzar-los oferint serveis educatius, garantint un bon govern, creant els serveis socials bàsics o bé ensenyant els pobres a emprar els seus propis recursos. D'aquestes maneres, els capitals individuals engeguen els mecanismes de la prosperitat.

Altres especialistes completen l'esquema causal identificant un marge estadístic de maniobra per a l'avenç de cada persona segons els seus esforços, és a dir, hi afegeixen que, a més a més, la mobilitat social és l'efecte de les inversions encertades en totes dues menes de capital. Fins i tot, per a alguns, la mobilitat és una mesura de la desigualtat molt millor que la distància estadística que separa els rics dels pobres o els instruïts dels illetrats. Aquesta distància era significativa en la societat industrial, perquè llavors les categories socials eren explícites i compactes. En canvi, a les societats posindustrials aquestes categories socials s'han individualitzat, cosa que ha d'amidar-se amb la mobilitat. Aquesta indica el fet que els fills atenyin una categoria socioeconòmica superior o inferior a la dels pares (mobilitat ascendent o descendent de posició), i també que algú canviï el seu nivell d'ingressos entre dos moments (mobilitat d'ingrés).

\section{La mobilitat de posició}

La hipòtesi sobre la mobilitat de posició postula que el desenvolupament econòmic, l'increment del nivell mitjà d'estudis i l'economia de la informació eixamplen les categories socioeconòmiques de "coll blanc», alhora que hi afavoreixen l'accés basat en el mèrit. Diversos estudis suggereixen que efectivament aquests canals són amplis, especialment als països desenvolupats. A partir de les taules d'orígens i destinacions socials als Estats Units dels anys 
seixanta, Blau i Duncan (1996 [1967]) van estimar que la mobilitat social era important malgrat la notable persistència de l'herència. Mentre que una gran proporció dels professionals independents, dels propietaris i dels agricultors provenia del mateix origen social, era més probable que els treballadors de "coll blanc» i de "coll blau" per compte aliè procedissin d'altres orígens. Entre aquests, la probabilitat de promoció (o mobilitat ascendent al llarg de la seva vida laboral) dels primers superava força la dels segons. Castells i Aoyama (1994) han analitzat l'estructura de l'ocupació dels països del G-7 entre 1920 i 1990; han observat un notable augment del sector de serveis a la producció, una ampliació de les categories de directiu, professional, tècnic i empleat no manual, $\mathrm{i}$ un creixement inferior de les categories de treballador no qualificat. Igualment, Clark i Lipset (1996) han reprès la hipòtesi de la mort de les classes recordant la individualització de l'organització laboral i de la vida familiar. Waters (1996 [1994]), en fi, ha suggerit que el mateix sistema d'estratificació s'ha transformat fins a tal punt que ha desembocat en un ordre postradicional d'estils de vida en comptes de l'ordre industrial de les classes. Requena (1998) ha avalat la tesi complementària sobre l'increment paral.lel de la modernització i de la mobilitat relativa. Comparant els EUA i Espanya, ha observat que al primer cas (més modern i desenvolupat) el coeficient d'associació entre els orígens i les destinacions socials és menor que al segon cas; ha notat també que en tots dos casos aquest coeficient tendeix a disminuir, però, en canvi, el nexe entre els estudis acabats i la destinació social es reforça. Dahan i Gaviria (2001) estimen aquesta mobilitat d'acord amb la variació del nivell d'estudis entre generacions (la igualtat de nivells entre germans, segons ells, indica la reproducció social), i arriben a la conclusió que als països més desenvolupats de l'Amèrica Llatina, com ara Xile, és més acusada que als menys desenvolupats.

\section{La mobilitat d'ingrés}

La hipòtesi sobre la mobilitat d'ingrés assenyala que les circumstàncies individuals són el factor més poderós de les trajectòries socials, i per tant expliquen les entrades i les sortides de la pobresa i de l'exclusió. Rosanvallon (1995: 202) entén que la «nova qüestió social» consisteix precisament a reconèixer aquest fet, ja que el perfil sociològic de les persones que han estat més de dos anys a l'atur o de les llars que no poden afrontar els seus deutes són tan heterogenis que no constitueixen cap grup específic. L'OCDE (1996, 2001a) ha remarcat aquesta millora dels salaris individuals al llarg de la vida (sobretot, la millora dels treballadors joves amb els anys) i la considerable freqüència de les «estades curtes» a sota del llindar de pobresa (amb el matís, això sí, que l'any típic viscut en la pobresa correspon a persones que han experimentat múltiples anys de pobresa). La tesi que la globalització ha pogut atallar la pobresa (allà on han crescut més les exportacions) confia en mecanismes similars que operen en el context del mercat lliure (vegeu el debat entre Wolf i Wade, 2002). 


\section{Algunes objeccions a les hipòtesis dels capitals individuals i la mobilitat}

Les anàlisis anteriors dels capitals individuals i de la mobilitat donen crèdit a l'estratègia d'induir els pobres a superar la seva condició pel seu compte. D'acord amb les seves conclusions, es pot esperar que pugin de categoria socioeconòmica i/o de nivell d'ingressos si fan servir la seva educació i les seves xarxes socials com a instruments per obtenir millors rendiments al mercat. En aquest apartat, recordaré diverses crítiques que, tanmateix, posen en dubte els passos d'aquest argument, sobretot els que fan referència 1) a l'experiència individual de la pobresa; 2) als lligams entre l'esfera domèstica i el mercat, a la suposada «amplada» dels canals de la 3) mobilitat de posició i 4) d'ingrés, i 5) als efectes de l'acció selectiva contra la pobresa.

En primer lloc, és dubtós que la mesura de seleccionar els pobres i activar els seus recursos sigui efectiva per reforçar el seu capital social, ensenyar-los a traure un millor profit dels seus recursos o donar-los formació. Sens dubte, aquesta esperança, i els temors correlatius de Coleman (1988) sobre els perjudicis de l'acció de l'Estat per al capital social, seran més o menys vàlids segons la informació que es pugui recollir empíricament en cada cas, però és notori que deixen de banda la influència dels possibles estigmes derivats d'una mesura que delimita el col-lectiu beneficiari. A més, tampoc no és versemblant que aquests efectes perversos siguin un accident que tan sols es derivi a vegades dels prejudicis populars o professionals. "La situació del pobre ajudat», escrivia Simmel (1998: 121), «el converteix, d'una banda, pel que fa a la seva situació individual, en l'objectiu extern de l'acció d'ajut, mentre que, d'altra banda, el col-loca enfront dels propòsits en conjunt de l'Estat com un objecte exempt de drets i com un material al qual ha de donar-se forma». És així que s'ha observat que una de les aplicacions més sistemàtiques de la lògica de la inducció, les polítiques d'inserció que l'Estat francès ha posat en pràctica durant els anys noranta, tan sols han imputat un estat «transitori permanent» (Castel, 1995) o de "semiocupació» (Mauger, 2001) als destinataris del programa. Aquests estudis no troben pas que la inserció de la majoria de beneficiaris hagi estat un èxit. Una altra cosa és el fet que s'hagi decidit de mantenir el subsidi malgrat tot, és a dir, s'hagi convertit la inserció en un estatus social a banda del seu resultat.

En segon lloc, és incompleta una anàlisi que restringeix l'articulació dels camps domèstic i mercantil als factors arrelats en el primer que contribueixen a assolir progressos relatius en el segon (Becker, 1987; Atria, 2003). Aquesta crítica procedent de la sociologia feminista (Acker, 1988) és gairebé una trivialitat avui en dia. Si més no, pel que fa a la lluita contra la pobresa, perquè posa en qüestió que la formació sigui tan profitosa per a les dones com per als homes, que aquest efecte sigui el mateix per a totes les edats o que es pugui atribuir la utilització dels serveis bàsics i el perfeccionament en l'ús dels recursos al conjunt de la llar (Mateo, 2001). Alhora, obvia els coneguts efectes perversos de sobrecàrrega de les intervencions selectives adreçades a les dones pobres per compensar l'empobriment que han causat els diversos programes d'ajustament estructural (Zabala, 1999, 2001). 
En tercer lloc, tampoc no estan lliures de discussió les correlacions entre el desenvolupament econòmic, el nivell d'estudis mitjà i la mobilitat social amb les quals s'estima l'eixamplament de la mobilitat de posició. Com és sabut, aquestes mesures fan referència a la mobilitat relativa, és a dir, a l'associació estadística entre les distribucions dels orígens (posició dels pares) i de les destinacions socials (posició dels fills), en contraposició a la mobilitat absoluta (el percentatge de persones que canvien de posició en comparar els orígens i les destinacions socials). Han merescut una crítica perquè no donen una mesura exhaustiva de la probabilitat de canviar de categoria socioeconòmica d'una generació a l'altra. En canvi, no es detecta una tendència cap a l'ampliació dels canals de mobilitat si es fa servir el model de la fluïdesa social, que calcula les probabilitats (mitjançant les dobles relacions, odds ratio) de canviar de casella a dins de la matriu d'orígens i destinacions (tenint en compte les altres caselles de la fila i de la columna on s'ubica, els totals d'aquesta fila i d'aquesta columna i el total de casos enregistrats a la taula). Aquesta altra estimació indica que la fluïdesa ha romàs constant per a les generacions nascudes durant el primer terç del segle vint en una mostra de països que abasta Alemanya (antiga RFA), Anglaterra, Austràlia, Escòcia, Estats Units, França, Hongria, Irlanda, Irlanda del Nord, Japó, Polònia i Suècia i Espanya (Erikson i Goldthorpe, 1996 [1992]; Carabaña, 1999). La fluïdesa social estima la mobilitat particular de cada classe i una gamma complexa de factors que determinen la mobilitat relativa total, a més de les variacions entre la distribució de les destinacions i la distribució dels orígens; és, doncs, un model molt més exhaustiu que els de Blau i Duncan, Castells i Aoyama, Requena (i no cal recordar que també Dahan i Gaviria).

En quart lloc, la tesi de la mobilitat d'ingrés també ha ensopegat amb obstacles empírics d'envergadura. D'entrada, la imatge abstracta d'un increment de la desigualtat d'ingrés compensat per una acceleració de la mobilitat (la qual cosa suavitzaria la desigualtat d'ingrés al llarg de la vida), obvia les diferències entre cohorts, per tal com es limita a retratar pocs anys (Creedy, 1998: 166). La lògica matemàtica més elemental també indica que la mobilitat dels individus a dins de la distribució dels ingressos pot reduir la desigualtat si es dirigeix cap a la mitjana, però pot agreujar-la si pren la direcció oposada (Creedy, 1998: 268). A més a més, diversos estudis han constatat que la majoria de pobres no experimenta gaire mobilitat, que les desigualtats entre els extrems s'han accentuat, que la mobilitat enregistrada entre quintils d'ingrés es concentra en els esglaons contigus al llindar de pobresa (Gardiner i Hills, 1999), que no s'obté pas una associació estadística entre la mobilitat i la desigualtat d'ingrés a escala de la Unió Europea (Prieto-Rodríguez, Salas i Álvarez- García, 2002), o que la relativa davallada de la pobresa d'ingrés a l'Amèrica Llatina s'explica simplement per l'aturada de la hiperinflació des de mitjan dècada dels noranta (Ganuza, Taylor i Morley, 1998).

En cinquè lloc, la bibliografia especialitzada tampoc no documenta que hagin reduït la pobresa en termes efectius alguns règims de benestar ni alguns programes socials que apunten tan sols a la població més pobra. Després de 
comparar els índexs de pobresa i els règims de la seguretat social amb una mostra de països de l'OCDE, Korpi i Palme (1998) han arribat a la conclusió que la seguretat social dels règims liberals, anglo-saxons o residuals, la qual és molt més selectiva que la dels altres règims, transfereix els ajuts als grups de menys ingressos per una via més directa, però acaba atorgant-los un pressupost menor. El resultat és que les desigualtats d'ingrés i els índexs de pobresa són menors als països on el règim de benestar ha adoptat les orientacions universalista $o$ corporativista. Salvant les distàncies, Cornia (2001) ha obtingut uns resultats anàlegs en avaluar els Fons Socials que el Banc Mundial va crear els anys vuitanta per compensar el fet que les desigualtats s'aguditzessin a molts dels països pobres que havien aplicat les mesures d'ajustament estructural. Segons les seves dades, aquests fons tan sols van contenir la pobresa en alguns casos, van ser molt ineficients a causa dels seus feixucs costos administratius i, desafortunadament, van esdevenir una arma política més que no pas una estratègia de consens.

\section{Conclusions i implicacions}

La proposta predominant per combatre la pobresa s'inspira en la lògica de la inducció. Vol definir clarament qui són els pobres i llavors interpel-lar-los perquè aprenguin a deseixir-se 0 , en altres paraules, perquè inverteixin els seus capitals humà i social a fi de travessar les barreres de classe social i d'ingrés. Es basa en l'esperança d'activar els capitals individuals i d'ampliar, en conseqüència, els canals de la mobilitat social, i recomana una intervenció «educativa» que ensenyi a traure profit d'aquests capitals. Combina, doncs, un diagnòstic amb unes recomanacions.

Els darrers anys, molts especialistes han intentat de reprendre les connexions entre els diagnòstics de la pobresa i les mesures que proposen els organismes internacionals. Respecte als països de l'OCDE, Rosanvallon (1995) i Giddens (2001) situen la tesi de la individualització "posindustrial» de les desigualtats en els fonaments de la seva proposta d'unes mesures més flexibles que la redistribució. Giddens (2001) interpreta que la desigualtat i la igualtat s'han convertit en un (d'altra banda enigmàtic) problema de realització personal (2001: 88), per tal com una elevada mobilitat d'ingrés ha desdibuixat els trets abans homogenis dels pobres. Per això reclama un active welfare que vinculi els drets a les responsabilitats per tal d'accelerar les sortides de la pobresa (2001: 106), i en tot cas només atengui especialment els pobres crònics (2001: 112-3). Respecte a les altres regions mundials, Rivero (1999a, 1999 b) atribueix genèricament a l'educació el poder de combatre la pobresa i promoure el desenvolupament, o Fukuyama (2001) busca una estratègia que no interfereixi en l'acumulació individual autònoma del capital humà i del capital social.

En la majoria dels casos només esmenten molt de pressa les hipòtesis dels capitals individuals i de la mobilitat, però és clar que aquestes constitueixen la base empírica de les seves recomanacions que les polítiques contra la pobresa 
s'han d'adequar a un canvi d'època o han de confiar en l'educació i les xarxes de relacions. Tanmateix, la recerca empírica no s'inclina pas a favor d'aquest diagnòstic, el qual recordem que deixa de banda la interacció entre els pobres i els serveis públics, oblida el camp domèstic d'activitat, es basa en unes mesures parcials de la mobilitat i confia en unes polítiques selectives que han demostrat uns efectes paradoxals. L'ombra d'aquest dubte, en bona lògica, afecta també l'eventual efectivitat de la inducció.

D'altra banda, molts advocats de la lògica de la inducció han avançat uns arguments que confonen certs diagnòstics sociològics amb la justificació normativa de les polítiques socials. És necessari trobar una nova fórmula adient als nous temps que viuen les diverses regions mundials? La discussió empírica sembla que doni més crèdit als qui reclamen una gamma de canvis que estenguin els drets de ciutadania mitjançant reformes institucionals (Robinson, 2001), fiscals (Townsend, 1996; Wright, 2001), educatives (Conell, 1997) o de la previsió social (Londoño, 2002) per eradicar la pobresa. En tot cas, un altre important avantatge d'aquest enfocament alternatiu és que no converteix l'anàlisi del canvi social en la premissa de l'argument, sinó que compara una circumstància empírica amb criteris normatius més abstractes. El fonament de les propostes no es deriva dels diagnòstics, sinó de les teories de la justícia social en què s'inspiren. Diluir una cosa en l'altra, com a mínim, no ajuda a promoure la discussió i ofusca la possible avaluació a mitjà termini del que es faci.

Finalment, les preocupacions perquè les polítiques socials hagin de ser adequades a un canvi d'època o perquè no provoquin cap distorsió a les accions individuals també encarnen un altre problema. Si és cert que la inducció substitueix una estratègia obsoleta basada a compensar els recursos insuficients (Rosanvallon, 1995; Giddens, 2001), o que una intervenció estatal excessiva malbarataria el potencial dels capitals humà i social (Fukuyama, 2001), el marge per compaginar les lògiques de la inducció i de l'extensió de la ciutadania és molt estret. Com a molt, l'estat ha de garantir l'educació bàsica, una pensió mínima i l'accés a l'aigua potable i als serveis sanitaris (Atria, 2003), però una complexa gamma d'institucions estatals, associacions i empreses privades han de fer el gruix de la feina d'identificar les possibilitats i experimentar la manera d'aprofitar-les en cada cas. En canvi, si no és obsoleta l'extensió dels drets civils, polítics i socials, ni és segur que perjudiqui la iniciativa de les persones, llavors seria plausible preguntar-se si no és més efectiva la lluita contra la pobresa quan és més gran l'accés als estudis secundaris posobligatoris o la renda es redistribueix d'acord amb els mateixos drets de ciutadania (en comptes de l'absència del mercat laboral). En suma, hi ha un espai de possibilitats més ampli que aplicar una prescripció única. La discussió pública sobre la ciutadania i les estratègies és més oberta que el tractament específic d'un col-lectiu "problemàtic», també és més facil de planificar-la a mitjà termini i deixa un marge més còmode perquè les decisions es prenguin i s'avaluïn democràticament. 


\section{Bibliografia}

ACKeR, J.(1988). «Class, Gender and Relations of Distribution». Signs, 13(3), p. 33-71. ATRIA, R. (2003). "Capital social: concepto, dimensiones y estrategias para su desarrollo». A CEPAL Capital social y reducción de la pobreza en América Latina y el Caribe [en línia], www.cepal.org, 02/03.

BECKER, G. (1987). «Desigualdad y movilidad intergeneracional». A Tratado sobre la familia (cap. 7). Madrid: Alianza.

BLAU, P.; DUNCAN, O.D. (1996 [1967]). «American Occupational Structure». A Holmwood, J. (dir.). Social Stratification. Cheltenham (Regne Unit): An Elgar Reference Collection.

CARABAÑa (1999). Dos estudios sobre movilidad intergeneracional. Madrid: ArgentariaVisor.

CARNOY, M. (1999). Globalization and educational reform: what planners need to know. París: UNESCO/ IIEP.

CASTEL, R. (1995). Les métamorphoses de la question social. París: Fayard.

CASTElls, M. (1998). La era de la información III: Fin de milenio. Madrid: Alianza.

CASTElls, M.; AOYAMA, Y. (1994). «Hacia la sociedad de la información: Estructura del empleo en los países del G-7 de 1920 a 1990». Revista Internacional del Trabajo, 113(1), p. 5-35.

CEPAL (2000). Equidad, desarrollo y ciudadania [en línia], www.eclac.es/publicacion, $11 / 02$.

- (2002). Panorama social de América Latina [en línia], www.eclac.es/publicacion, $03 / 03$.

Clark, T.N.; LiPSET, S.M. (1996). «Are social classes dying?». A LeE, D.J.; TURNER, B. (eds.). Conflicts about Class. Debating Inequality in late Industrialism. Londres i Nova York: Longman.

Coleman, J. (1988). «Social Capital in the Creation of Human Capital». American Journal of Sociology, 94. Suplement, p. 95-120.

CONDORCET (1995 [1793]). Esquisse d'un Tableau Historique des Progrès de l'Esprit Humanine [en línia], ishi.lib.berkeley.edu, 09/01.

CONELL, R.W. (1997). Escuelas y justicia social. Madrid: Morata.

CONSEJO EUROPEO DE LisBOA (2000). «Modernización del modelo social europeo mediante la inversión en capital humano y la constitución de un estado activo de bienestar». Conclusiones de la Presidencia [en línia] http://ue.eu.int, 04/2004.

CorniA, G.A. (2001). "Social Funds in Stabilization and Adjustment Programmes: A Critique». Develompent and Change, 32, p. 1-32.

CreEDy, J. (1998). The Dynamics of Inequality and Poverty. Cheltenham (Regne Unit): Edward Elgar.

Dahan, M.; Gaviria, A. (2001). «Sibling Correlations and Intergenerational Mobility in Latin America». Economic Development and Cultural Change, 49, p. 537-554.

Develoment Assistance Committee (DAC/ OECD) (2001). In the Face of Poverty. Meeting with Global Challenge Through Partnership [en línia], www.oecd.org/ dac/poverty, 15/05/02.

ENGELS, F. (1965 [1845]). La situación de la clase obrera en Inglaterra. Barcelona: Editorial Futuro.

Erikson, R.; Goldthorpe, J. (1996 [1992]). «Concepts, Data and Strategies of Equiry: The Constant Flux: A Study of Class Mobility in Industrial Societies». A 
Holmwood, J. (dir.). Social Stratification. Cheltenham (Regne Unit): An Elgar Reference Collection.

FuKuYAma, F. (2001). «Social capital, civil society and development». Third World Quarterly, 22(1), p. 7-20.

Gardiner, K.; Hills, J. (1999). «Policy Implications of New Data on Income Mobility». The Economic Journal, 109, F91- F111.

Giddens, A. (2000). "The Question of Inequality». A Giddens, A. The Third Way and Its Critics. Londres: Polity, p. 88-114.

ILO (2001). «Poverty Reduction and Decent Work in a Globalizing World». Working Papers on the Social Dimension of Globalization, GB.280/WP/SDG/1 [en línia], http://www.ilo.org/publiclenglish/standards/relm/gb/docs/gb280/pdf/sdg-1.pdf, $04 / 2004$.

KORPI, W. (1999). «Faces of Inequality: Gender, Class and Patterns of Inequalities in Different Types of Welfare States». Social Politics: International Studies in Gender, State and Society, 10.

Korpi, W.; Palme, J. (1998). "The Paradox of Redistribution and Estrategies of Equality: Welfare State Institutions, Inequality and Poverty in the Western Countries». American Soc. Review, 63 (5), p. 661-688.

LONDOÑO, J.L. (2000). Ideas para una estrategia de trabajo del PNUD en sectores sociales. Informe de Consultoría para PNUD [en línia] www.undp.org, 05/2002.

MALTHUS, T.R. (1985 [1798]). Un assaig sobre el principi de població. Barcelona: Edicions 62.

Marshall, A. (1966 [1899]). Principles of Economics. An Introductory Volume. Londres: Macmillan.

Marshall, Th. (1992 [1950]). «Ciudadanía y clase social». A Marshall, Th.; BotTomore, T. Ciudadanía y clase social. Madrid: Alianza.

MAteO, M.A. (2001). «Desiguales, pobres y excluidas. Lecciones metodológicas desde la (ausente) perspectiva de género». Papers. Revista de Sociologia, 65, p. 167-179.

MAUGER, G. (2001). «Les politiques d'insertion. Une contribution paradoxale à la déstabilisation du marché du travail». Actes de la Recherche en Sciences Sociales, 136-137, p. 5-14.

MORLEY, S. (1998). «La pobreza en tiempos de recuperación económica y reforma en América Latina: 1985-1995». A GanuZA, A.E.; TAYlor, L.; Morley, S. Política económica y pobreza en América Latina y el Caribe. Madrid: Ediciones Mundi Prensa/ PNUD.

Murray, Ch. (1999). «And Now For the Bad News. Symposium: The Underclass and America's Future». Society, 37, 1(243), p. 12-15.

OCDE (1996). «Earnings inequality, low-paid employment and earnings mobility». Employment Outlook. París: OCDE [en línia], www.oecd.org, 03/03.

- (2001a). "When Money is Tight: Poverty Dynamics in OECD Countries». Employment Outlook. París: OCDE [en línia], www.oecd.org, 03/03.

- (2001b). Education at a Glance. París: OCDE [en línia], www.oecd.org, 12/2001.

- (2001c). Programme for International Student Assessment [en línia], www.pisa.oecd.org, $09 / 02$.

PNUD (1997). Desarrollo humano para erradicar la pobreza. Informe sobre Desarrollo Humano. Barcelona: Ediciones Mundi Prensa.

- (2000). Informe sobre el desenvolupament humà. Barcelona: Centre UNESCO de Catalunya.

- (2002). Informe sobre desarrollo humano [en línia], www.undp.org, 05/03. 
Prieto-Rodríguez, J.; Salas, R.; Álvarez-García, S. (2002). «Movilidad social y desigualdad económica». Documentos de Trabajo del Instituto de Estudios Fiscales, 7/02 [en línia], www.minhac.eslief, 12/02.

REQUena SANTOS, Félix (coord.) (1999). Sociedad, cultura y desarrollo. Apuntes para un análisis comparado entre España y Estados Unidos. Málaga: Universidad de Málaga y Universidad de Almería.

Rivero, J. (1999a). Educación y exclusión en América Latina. Reformas en tiempos de globalización. Buenos Aires: Miño y Dávila.

- (1999b). «Educación y pobreza: políticas, estrategias y desafíos». Revista Paraguaya de Sociología, 36(106), p. 107-144.

RoBinson, J. (2001). «Where Does Inequality Come From? Ideas and Implications for Latin America». OECD Development Centre. Technical Papers, 188 [en línia], www.oecd.org/dev/Technics, 10/02.

Rosanvallon, P. (1995). La nouvelle question sociale. Repenser l'état-providence. París: Seuil.

SChumpeter, J. (1986 [1950]). Imperialismo. Clases sociales. Madrid: Tecnos.

SiMMEL, G. (1988). Sociologia. Barcelona: Edicions 62.

Townsend, P. (1996). A Poor Future. Can We Counter Growing Poverty in Britain and Across the World? Londres: Lemos \& Game.

WATERS, M. (1996). «Succession in the stratification system». A LEE, D.J.; TuRnER, B. (eds.). Conflicts about class. Debating inequality in late industrialism. Londres i Nova York: Longman.

WILENSKI, H.L. (1975). The Welfare State and Equality. Structural and Ideological Roots of Public Expenditure. Berkeley. University of Californa Press.

WOLF, M.; WADE, R. (2002). «3-Round Letter Exchange on World Poverty and Inequality». Centre for the Study of Globalisation and Regionalisation, $5^{\text {th }}$ Annual Conference [en línia], www.warwick.ac.uk/fac/soc/CSGR/Pwade.pdf, 04/03.

World BANK (2001). World Development Report 2000/2001. Attacking Poverty. Overview [en línia], www.worldbank.org, 05/2002.

Wright, E.O. (1997). Class Counts. Comparative Studies in Class Analysis. Nova York: Cambridge University Press.

- (2001). «Propuestas utópicas reales para reducir la desigualdad de ingresos y riqueza». A Gargarella, R.; Ovejero, F. (comps.). Razones para el socialismo. Barcelona: Paidós.

ZABALA, I. (1999). «Un viaje a través del tiempo: treinta años de pensamiento económico feminista en torno al desarrollo». A CARRASCO, C. (ed.). Mujeres y economía. Barcelona: Icaria.

- (2001). «El desarrollo humano desde una perspectiva de género». A IBARRA, P.; UNCETA, K. (coords.). Ensayos sobre el desarrollo humano. Barcelona: Icaria. 